University of Nebraska - Lincoln

DigitalCommons@University of Nebraska - Lincoln

\title{
Polygyny and Female Breeding Failure Reduce Effective Population Size in the Lekking Gunnison Sage-Grouse
}

Julie R. Stiver

University of Nebraska - Lincoln

Anthony D. Apa

Colorado Division of Wildlife (Grand Junction, Colo.), tony.apa@state.co.us

Thomas E. Remington

Colorado Division of Wildlife (Denver, Colo.), Tom.Remington@state.co.us

Robert M. Gibson

University of Nebraska - Lincoln, rgibson@unl.edu

Follow this and additional works at: https://digitalcommons.unl.edu/bioscifacpub

Part of the Life Sciences Commons

Stiver, Julie R.; Apa, Anthony D.; Remington, Thomas E.; and Gibson, Robert M., "Polygyny and Female Breeding Failure Reduce Effective Population Size in the Lekking Gunnison Sage-Grouse" (2008). Faculty Publications in the Biological Sciences. 225.

https://digitalcommons.unl.edu/bioscifacpub/225

This Article is brought to you for free and open access by the Papers in the Biological Sciences at DigitalCommons@University of Nebraska - Lincoln. It has been accepted for inclusion in Faculty Publications in the Biological Sciences by an authorized administrator of DigitalCommons@University of Nebraska - Lincoln. 


\title{
Polygyny and Female Breeding Failure Reduce Effective Population Size in the Lekking Gunnison Sage-Grouse
}

\author{
Julie R. Stiver ${ }^{\mathrm{a},{ }^{*}}$, Anthony D. Apa ${ }^{\mathrm{b}}$, Thomas E. Remington ${ }^{\mathrm{c}}$, Robert M. Gibson ${ }^{\mathrm{a}}$ \\ aSchool of Biological Sciences, University of Nebraska-Lincoln, Lincoln, Nebraska, U.S.A. \\ ${ }^{\mathrm{b} C}$ Colorado Division of Wildlife, Grand Junction, Colorado, U.S.A. \\ ${ }^{\circ}$ Colorado Division of Wildlife, Denver, Colorado, U.S.A. \\ Authors' E-mail addresses: jrstiver@unlserve.unl.edu, Tony.Apa@state.co.us, Tom.Remington@state.co.us, rgib- \\ son2@unl.edu.
}

\begin{abstract}
Populations with small effective sizes are at risk for inbreeding depression and loss of adaptive potential. Variance in reproductive success is one of several factors reducing effective population size $\left(N_{e}\right)$ below the actual population size $(N)$. Here, we investigate the effects of polygynous (skewed) mating and variation in female breeding success on the effective size of a small population of the Gunnison sage-grouse (Centrocercus minimus), a ground nesting bird with a lek mating system. During a two-year field study, we recorded attendance of marked birds at leks, male mating success, the reproductive success of radio-tagged females, and annual survival. We developed simulations to estimate the distribution of male reproductive success. Using these data, we estimated population size $(\widehat{N})$ and effective population size $N_{e}$ for the study population. We also simulated the effects of population size, skewed vs. random mating, and female breeding failure on $N_{e}$. In our study population, the standardized variance in seasonal reproductive success was almost as high in females as in males, primarily due to a high rate of nest failure $(73 \%)$. Estimated $N_{e}(42)$ was $19 \%$ of $\widehat{N}$ in our population, below the level at which inbreeding depression is observed in captive breeding studies. A high hatching failure rate $(28 \%)$ was also consistent with ongoing inbreeding depression. In the simulations, $N_{e}$ was reduced by skewed male mating success, especially at larger population sizes, and by female breeding failure. Extrapolation of our results suggests that six of the seven extant populations of this species may have effective sizes low enough to induce inbreeding depression and hence that translocations may be needed to supplement genetic diversity.
\end{abstract}

Keywords: Lek, Reproductive success, Variance, Mating system, Centrocercus

Article history: Received January 26, 2007; received in revised form October 16, 2007; accepted October 27, 2007; available online February 20, 2008.

\section{Introduction}

Effective population size $\left(N_{e}\right)$ is an important parameter in conservation biology (Lande and Barrowclough, 1987; Frank ham et al., 2002). It is defined as the size of an idealized population of breeding adults that would experience the same(1) loss of heterozygosity, (2) change in the averageinbreeding coefficient, or (3) change in variance in allele frequency through genetic drift as the actual population (Futuyma, 1998; Frankham et al., 2002). As effective population size decreases, the rate of loss of allelic diversity via genetic drift increases. Two consequences of this loss of genetic diversity, reduced fitness through inbreeding depression and reduced response to sustained directional selection ("adaptive rate of potential"), are thought to elevate extinction risk (Frankham et al., 2002; Frankham, 2005). Captive breeding studies suggest $N_{e}$ should exceed 50-100 to avoid inbreeding depression. Mathe- matical models suggest that $N_{e}$ should be at least 500 to retain adaptive potential, though some estimates are as high as 5,000 (Frankham et al., 2002). Estimating $N_{e}$ could therefore indicate whether a population might be at risk of from either consequence.

The effective size of a population is often much less than its actual size $(N)$. Fluctuating population size, variance in reproductive success, and unequal sex ratios all reduce $N_{e}$ (Wright, 1938; Frankham, 1995). Fluctuating population size has the largest effect and unequal sex ratios the least. We focus here on the effect of variable reproductive success.

In a population of constant size, increasing the variance in reproductive success in either sex will reduce $N_{e}$ (Hill, 1972; Nunney, 1993, 1996; Hedrick, 2005). Mechanisms that elevate variance in reproductive success will often differ between the sexes. For males, the mating system will be the primary determinant of vari- 
ance (Shuster and Wade, 2003). Polygyny is expected to produce higher variance in male reproductive success than alternative mating systems because variance will increase as fewer males monopolize more mates. The effect of polygyny on $N_{e}$ has been examined both theoretically (Nunney, 1993; Engen et al., 2007) and in multiple empirical studies with a focus on mammals (Nunney and Elam, 1994; Storz et al., 2001, 2002). Except in polyandrous mating systems, variance in female reproductive success may depend more on the proportion of females that reproduce and the variance in offspring produced per successful female than on the numbers of mates (Nunney, 1993; Frankham et al., 2002). However, few empirical studies have investigated the extent to which variation in female reproductive success affects $N_{e}$ (Turner et al., 1999; Kelly, 2001).

The Gunnison sage-grouse (Centrocercus minimus) is a recently described bird species existing in seven small populations in southwestern Colorado and southeastern Utah (Young et al., 2000; Gunnison Sage-grouse Rangewide Steering Committee, 2005). In 2005, population size estimates ranged from 40 birds in the smallest populations to approximately 2,500 in the largest. Most populations are geographically isolated from each other and exhibit low genetic diversity (OylerMcCance et al., 2005). In addition to any effects of population fragmentation, effective population size might be relatively low in Gunnison sage-grouse for at least three reasons.

First, $N_{e}$ could be depressed because the species' polygynous lek mating system, in which a relatively small proportion of males on leks perform most copulations (Wiley, 1973; Young et al., 2000), elevates the variance in male reproductive success. The potential for mating skew to decrease Ne in lekking grouse has been recognized previously (Bellinger et al., 2003; Johnson et al., 2003, 2004; Bouzat and Johnson, 2004), but the magnitude of the effect has not been studied. Additionally, studies of other lekking birds suggest that the effect of mating skew is likely to be a function of population size because mean lek size increases with population size (Bradbury et al., 1989) and the distribution of matings within a lek becomes less skewed as lek size increases (Alatalo et al., 1992; Widemo and Owens, 1995, 1999).

Second, effective population size might be reduced by nest predation because this increases the variance in female reproductive success. There have been few studies of nest success in Gunnison sage-grouse (Young, 1994), but in the closely related greater sage-grouse (C. urophasianus) nest success rates average $47 \%$ (range $14-86 \%$; Schroeder et al., 1999). This range of values suggests that variance in reproductive success could sometimes be high in females as well as males. Finally, if this species exhibits similar demography to the greater sage-grouse, $N_{e}$ may be lowered by a strongly female-biased sex ratio among breeding individuals. The bias arises from both a female-biased population sex ratio (Schroeder et al., 1999) and sexual bimaturism, in which most males do not compete reproductively until in their second year of life while females nest in their first year (Wiley, 1974).

In this paper, we estimate both the population size ( $\tilde{N})$ and effective population size $\left(N_{e}\right)$ of a small population of Gunnison sage-grouse. We use a mark-resight method to estimate population size (Walsh et al., 2004). We combine demographic parameter estimates derived from both field data and simulations of male reproductive success distributions to estimate $N_{e}$ using a demographic method derived by Nunney (1993, 1996). Additionally, we use simulations to investigate how $N_{e}$ is affected by: (1) the potential interaction between lek mating and population size, (2) the skewed lek mating system versus a null hypothesis of random mating, and (3) variance in female reproductive success caused by female breeding failure.

\section{Methods}

\subsection{Study area}

We studied the second largest population of Gunnison sage-grouse, located in the San Miguel Basin, Montrose and San Miguel counties, Colorado, United States $\left(38^{\circ} \mathrm{N} 108^{\circ} \mathrm{W}\right)$, from 2003 to 2004 . Elevations in the study area range from 1,900 to $2,800 \mathrm{~m}$. Below 2,300 m, Gunnison sage-grouse habitat is characterized by sagebrush (Artemisia spp.), greasewood (Sacrobatus spp.) and salt brush (Atriplex spp.). At higher elevations the habitat is characterized by sagebrush and Gambel oak (Quercus gambelii). Eight leks were active in the population at the start of the study.

\subsection{Field methods}

In both years, we captured birds in winter flocks, prior to April 1, with spotlights and nets (Giesen et al., 1982; Wakkinen et al., 1992). We captured additional birds within $1.5 \mathrm{~km}$ of leks during late April and early May 2003. We classified birds by age (yearling vs. adult) and gender using size and primary feather molt (Crunden, 1963). Males were fitted with $3.2 \mathrm{~g}$ tail-mounted radio transmitters while females were fitted with $14 \mathrm{~g}$ necklace-mounted transmitters (Holohil Systems, Inc.). All birds were marked with a unique color band combination. Over both years we marked 34 males (15 adults, 19 yearlings) and 39 females (29 adults, 10 yearlings). Five males and seven females surviving from a previous study were also included. Sample sizes for most analyses are less than these totals, due to contextual restrictions on sample composition.

Each year we monitored six of the eight active leks, excluding two inaccessible high elevation leks. We 
monitored leks daily following previously described methods (Gibson et al., 1991) from late March to early May. Observations started one hour before sunrise and continued until the last bird left the lek or the birds stopped displaying. These observations provided data on male mating success and lek attendance by marked and unmarked birds of both sexes.

Following the morning display, we triangulated the locations of all radio-tagged birds to detect mortality, and to determine whether a female's movements indicated she had localized to a possible nesting location (Gibson and Bachman, 1992). Approximately two weeks after a female restricted her movements, we located her visually to confirm incubation and recorded nest location with a global positioning system, taking care not to flush her from the nest. We did not return to a nest until either the female was triangulated away from it for three consecutive days or her predicted hatching date approached (based on a $27 \mathrm{~d}$ incubation period; Schroeder et al., 1999). Once a female left a nest, we determined whether it was successful (at least one egg had hatched), abandoned, or destroyed by a predator. We counted eggshells (if present), examined them for presence of an embryonic membrane as evidence of hatching, and also opened any unhatched eggs to determine fertility. We checked egg-based estimates of chick numbers hatched by locating females and counting their broods within $48 \mathrm{~h}$ of hatching. In every case the number of chicks matched the number of hatched eggs.

\subsection{Estimation of population size $(\tilde{N})$}

For each year we made separate estimates of male and female numbers based on peak daily counts of marked and unmarked birds seen at monitored leks. Following Walsh et al. (2004), we generated estimates using Bowden and Kufeld's (1995) mark-resight method implemented in NOREMARK software (White, 1996). Population size ( $(\widehat{N})$ was computed as the sum of male and female estimates. We estimated population size for a focal area in which birds were trapped and leks extensively monitored, excluding the two high elevation leks. We included sightings of all marked birds captured prior to and alive as of April 1, except for those (two females and a male in 2003, and a female in 2004) that could not have been observed because they moved to the unmonitored high elevation area. To avoid overestimating the attendance of radiotagged birds, marked sighting records excluded individuals whose radio signals were detected during lek observations but that were not also visually identified on the lek. We used daily lek observations collected between April 1 and April 20, excluding four days each year when heavy snow made individual identification impossible. After April 20 grass had grown too high to allow reliable identification of color bands.

We also computed an adjusted population size estimate for the entire San Miguel population, by adding a component for the high elevation leks based on seasonal high count data collected by the Colorado Division of Wildlife (unpublished). A seasonal high count is the highest of four daily counts made during the breeding season. High counts underestimate male population size because not all males attend leks daily (Walsh et al., 2004) and do not include females. A simulated high count sampling procedure applied to data from our focal study area indicated that high counts represent an average of $58 \%$ of our mark-resight male population estimate. Therefore we estimated the size of the entire San Miguel Basin as focal area mark resight estimate $+(1+$ females per male $)$ * high elevation leks high count/0.58. We computed females per male from the sex-specific mark resight population estimates (Section 3.1.1).

\subsection{Estimation of effective population size}

To estimate $N_{e}$ we used Nunney (1993) equation A2:

$N_{e}=\left[4 r(1-r) N_{\text {breeders }} T\right] /\left\{A_{m}(1-r)+A_{f} r\right]-\left(2 r / b_{f}\right)$

$\left.\left.+\left[I_{b_{m}}(1-r)+I_{b_{f}} r\right]+A_{m} I_{A_{m}}(1-r)+A_{f} I_{A_{f}} r\right]\right\}$

where $r$ is the sex ratio among potential breeders expressed as the proportion of males, Nbreeders is the number of potentially breeding individuals, $T$ is the generation time averaged across both sexes, $A_{f}$ and $A_{m}$ are the reproductive lifespans of females and males, $b_{f}$ is mean seasonal female reproductive success, $I_{b_{f}}$ and $I_{b_{m}}$ are the standardized variances (variance $/$ mean $^{2}$ ) in seasonal reproductive success of females and males, and $I_{A_{f}}$ and $I_{A_{m}}$ are the standardized variances in lifespan of females and males. The estimation of each parameter is described below and summarized in Table 1.

\subsection{1. $N_{\text {breeders }}$ and sex ratio $(r)$}

We computed these parameters from our sex-specific estimates of population size (Section 2.3). We defined $N_{\text {breeders }}$ as the total number of birds in the population that had reached the age of reproductive maturity, which is the first year of life for females and the second year for males (Wiley, 1974). $N_{\text {breeders }}$ was therefore all females plus adult males while $r$ was adult males divided by all females. To obtain the number of adult males, we multiplied the male population size estimate by an estimate of the proportion of adults, thereby excluding the yearling population segment. We estimated the proportion of adults by projecting annual survival estimates (Section 2.4.2) into a life table. Our estimate of $58 \%$ adults is close to the proportion of adults among captured males (53\%). Effective population size 


$\begin{array}{ll}\text { Table } 1 \text { - Input parameters for estimation of } N_{e} \text { using Nunney's (1993) equation A2 } \\ \text { Parameter } & \text { Definition } \\ N_{\text {breeders }} & \text { Number of potential breeders } \\ r & \text { Proportion of males among potential breeders } \\ A_{f} & \text { Female reproductive lifespan } \\ A_{m} & \text { Male reproductive lifespan } \\ T_{f} & \text { Female generation time } \\ T_{m} & \text { Male generation time } \\ T & \text { Average generation time } \\ b_{f} & \text { Mean female reproductive success (brood size) } \\ I_{b_{f}} & \text { Standardized variance in female reproductive success } \\ I_{b} & \text { Standardized variance in male reproductive success } \\ I_{A_{f}} & \text { Standardized variance in female reproductive lifespan } \\ I_{A_{m}} & \text { Standardized variance in male reproductive lifespan }\end{array}$

$\begin{array}{ll}\text { Derivation } & \text { Estimate } \\ \text { Adult males }+ \text { all females } & 145 \\ \text { Adult males: } N_{\text {breeders }} & 0.21 \\ A_{f}=1 /\left(1 v_{f}\right) & 1.82 \\ A_{m}=1 /\left(1 v_{m}\right) & 1.38 \\ T_{f}=M_{f}-1+A_{f} & 1.82 \\ T_{m}=M_{m}-1-A_{m} & 2.38 \\ \left(T_{f}+T_{m}\right) / 2 & 2.10 \\ \text { Field data } & 0.90 \\ \text { Field data } & 4.70 \\ \text { Simulations } & 5.10 \\ v_{f} & 0.45 \\ v_{m} & 0.273\end{array}$

The calculation derivations are from Nunney and Elam (1994). $M_{f}$ and $M_{m}$ are ages at maturity for females and males $\left(M_{f}=1, M_{m}=2\right) ; v_{f}$ and $v_{m}$ are annual survival of females and males (values in Section 3.1.3).

estimates obtained using these two values differed by less than 1 individual or $2 \%$.

\subsubsection{Annual survival and derived parameters}

Annual survival estimates of potential breeders of both sexes $\left(v_{f}\right.$ and $\left.v_{m}\right)$ were necessary to calculate generation time $(T)$, sex specific reproductive lifespans $\left(A_{f}\right.$ and $\left.A_{m}\right)$ and standardized variances in sex specific reproductive lifespan $\left(I_{A_{f}}\right.$ and $\left.I_{A_{m}}\right)$ as described in Table 1. We calculated annual survival as the proportion of marked birds alive on April 1, 2003 that survived to March 31, 2004. Survival of radio-tagged females was monitored by radiotracking. During the field season (March-June), we also radiotracked males to monitor mortality. Because males shed their tail-mounted transmitters during the summer molt, subsequent survival was based on recapture or visual identification at leks in 2004. Reliance on resighting could lower detection probability and might therefore bias male survival estimates downwards. However, this is unlikely to have affected our results substantially because seven of eight males died while the transmitters were still attached. In order to compute population age structure (Section 2.4.1), we made a similar estimate of yearling male survival (J.R. Stiver, unpublished data).

\subsubsection{Female reproductive success}

This was measured as brood size, the number of chicks found with a female within $48 \mathrm{~h}$ of hatching. Females whose nests failed were assigned zero chicks. We used brood size to estimate mean annual female reproductive success $\left(b_{f}\right)$ and its standardized variance $\left(I_{b_{f}}\right)$. To ensure consistency between census and effective population size estimates, the sample included all marked females alive on April 1 of each year. We pooled data from yearling and adult females to estimate female reproductive parameters because preliminary analyses revealed no statistically significant age differences. We also made separate estimates of two components of female reproductive success: the proportion of marked females reproducing, i.e. hatching at least one chick, and mean brood size per successful female. These values were used when generating simulated distributions of reproductive success (Sections 2.4.4 and 2.5.1). Finally, for successful nests we computed hatching failure rate as the number of unhatched eggs present in the nest after brood departure divided by the total number of hatched and unhatched eggs.

\subsubsection{Variance in male reproductive success $\left(I_{b_{m}}\right)$}

We estimated this parameter by a simulation procedure using data on (i) the distribution of males and females among leks, (ii) the distribution of matings among males within leks, and (iii) variation in female reproductive success (Section 2.4.3). The simulation was performed using PopTools v2.6.6 (Hood, 2005). It started with the input of male and female population sizes and involved the following steps:

i. We first determined how many leks would typically form in a population of the simulated size from a linear regression of lek numbers on male population size. We generated the regression using four years of lek count data (2001-2004) from the six smaller Gunnison sage-grouse populations (Gunnison Sage-grouse Rangewide Steering Committee, 2005). These data report male numbers as seasonal high counts which represent $58 \%$ of the

Table 2 Uncorrected proportions of males on leks of different size rank, sorted from largest (1) to smallest (further details in text Section 2.4.4)

$\begin{array}{ll}\text { Lek rank } & \text { Uncorrected proportion of males } \\ 1 & 0.826-0.247 \ln (l), p=0.0001, n=25 \\ 2 & 0.382-0.074 \ln (l), p=0.03, n=24 \\ 3 & 0.145 \pm 0.019, n=19 \\ 4 & 0.095 \pm 0.011, n=13 \\ 5 & 0.082 \pm 0.014, n=8 \\ 6 & 0.064 \pm 0.094, n=6 \\ 7 & 0.039 \pm 0.072, n=5 \\ 8 & 0.032 \pm 0.008, n=4\end{array}$


Table 3 - Sample sizes, sighting records, and annual mark-resight population estimates $(\widehat{N})$ for the monitored portion of the San Miguel Basin Gunnison sage-grouse population, 2003-4

\begin{tabular}{lcccccccc} 
Population segment & \multicolumn{2}{c}{ Marked individuals } & \multicolumn{2}{c}{ Marked bird sightings } & \multicolumn{2}{c}{ Unmarked bird sightings } & \multicolumn{2}{c}{$\tilde{N}(95 \% \mathrm{CI})$} \\
Males & 2003 & 2004 & 2003 & 2004 & 2003 & 2004 & 2003 & 2004 \\
Females & 13 & 14 & 89 & 72 & 263 & 235 & $50(34-73)$ & $57(37-89)$ \\
& 20 & 22 & 22 & 16 & 109 & 86 & $105(55-202)$ & $123(64-238)$
\end{tabular}

Numbers of marked individuals refer to birds alive on April 1 of each year that contributed to the population estimate.

population estimated by our mark resight method (Section 2.3). Therefore, we converted high counts to male population size by dividing by 0.58 . The fitted regression, which was forced through 1,1 so that a population with one male had one lek, was lek number $=0.93+0.07 *$ male population size $\left(F_{1,22}=28.6, p<0.0001\right)$.

ii. Males were next assigned to leks. We estimated the proportional distribution of males among leks from the dataset used to estimate lek number. For each population and year we first computed the proportion of males in each lek, sorted from largest to smallest. We then pooled the data and, for each lek rank, regressed the proportion of males on the number of leks in the population. For the first and second largest leks, this proportion decreased significantly in populations with more leks (Table 2). For the lower ranked leks, this relationship was not significant and we therefore computed a mean proportion for each lek rank (Table 2). Finally, the "uncorrected" proportions from Table 2 were normalized by dividing the value for each lek rank by the sum of uncorrected proportions for the number of leks in the simulation. Once males had been settled, females were distributed in proportion to the number of males assigned to each lek, reflecting a pattern documented at greater sage-grouse leks (Gibson, 1996).

iii. Within each lek females (matings) were assigned to adult males based on Kokko and Lindström (1997) mating skew model:

$$
E\left[p_{\text {rark }}\right]=\frac{\lambda(1-\lambda)^{\mathrm{rank}-1}}{1-(1-\lambda)^{n}}
$$

where $E\left[p_{\text {rank }}\right]$ is the expected proportion of matings obtained by male of a given rank (the most successful male has rank of one), $n$ is the number of males on the lek, and $\lambda$ is a mating skew parameter that that varies with lek size. Lambda $(\lambda)$ can take values from zero (random mating) to one (all matings monopolized by one male). We estimated the relationship between $\lambda$ and lek size $(n)$ using data from five leks with sufficient data from this study and eight greater sage-grouse leks (Gibson et al., 1991; Semple et al., 2001). We computed $\lambda$ for each dataset using Skew Calcula- tor software (Nonacs, 2003) and then fitted Kokko and Lindström's (1997) function

$$
1=\frac{1}{1+a n^{b}}
$$

using least squares. Fitted parameter estimates were $a=0.093$ and $b=0.875$.

iv. To convert matings to offspring sired, each female was randomly assigned a nesting success

a

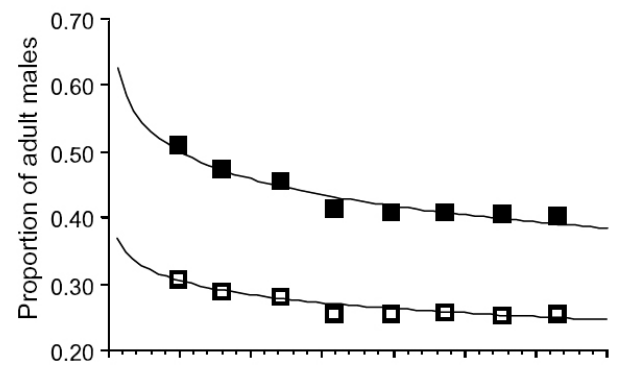

b
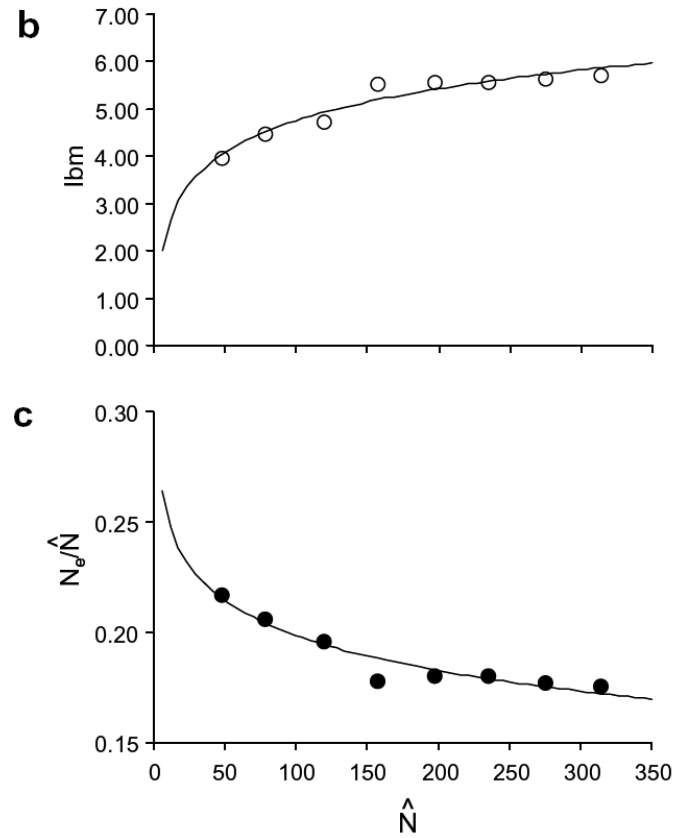

Figure 1 - Effects of population size $(\widehat{N})$ on (a) the proportion of males mating (solid squares; $y=0.60 .05 \ln (x) ; p=0.0001$ ) and reproducing (open squares; $y=0.30 .02 \ln (x) ; p=0.0002$ ), (b) the standardized variance in male reproductive success (Ibm: $y=0.4+1.0 \ln (x) ; p$ $<0.0001)$, and c) $N_{e} / \widehat{N}(y=0.4-0.03 \ln (x) ; p<0.0001)$. 


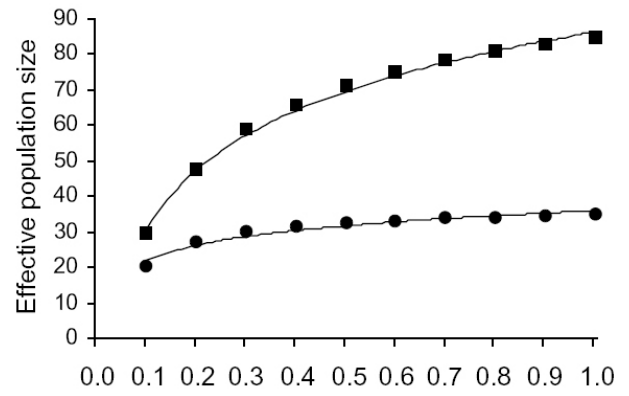

Figure 2 - Effective population size plotted as a function of the proportion of females hatching chicks under simulated lek mating (circles) and random mating (squares). Simulations are based on a census population size of 147 .

value ( 0 or 1$)$ based on the observed proportion of marked females that reproduced (Section 2.4.3). Successful females were then assigned a number of chicks drawn randomly from a normal distribution with the observed mean and variance in brood size per successful female. Chicks sired by each male were then summed over his assigned females.

v. After step (iv), we computed the mean, variance and standardized variance $\left(I_{b_{m}}\right)$ in male reproductive success (chicks sired per male), and the percentages of males mating and reproducing. Means of these values were computed after 1,000 simulations.

\subsection{Simulated effects on effective population size}

Besides estimating $N_{e}$ for our study population, we simulated the effects on $N_{e}$ of variation in (i) population size, (ii) mating system and (iii) female breeding failure. These analyses followed the methods described in Section 2.4, with the following changes.

\subsubsection{Female reproductive success}

For all simulations, empirical estimates of $b_{f}$ and $I_{b_{f}}$ (Section 2.4.3) were replaced by values based on simulated data. We randomly assigned a nest success value ( 0 or 1$)$ to each female based on a specified probability that a female successfully reproduced. Successful females were then assigned a number of chicks drawn randomly from a normal distribution with the mean and variance in brood size per successful female observed in our study population. Using the observed proportion of females reproducing, this procedure produced estimates of $b_{f}$ and $I_{b_{f}}$ almost identical to the empirically derived values (Section 2.4.3) indicating that it accurately replicated the distribution of female reproductive success. The same values of nest success and brood size were used in the corresponding simulation of male reproductive success $\left(I_{b f}\right.$ Section 2.4.4).

\subsubsection{Effect of population size}

In these simulations, changing population size affects the numbers and sizes of leks, which in turn affect the standardized variance in male reproductive success by altering the distribution of matings. We simulated eight population sizes ranging from 47 to 313 birds. The smallest population had 15 males and 32 females while the largest had 100 males and 213 females, thus maintaining the observed population sex ratio. We used the observed proportion of females reproducing when computing $I_{b_{f}}$ and $I_{b_{m}}$.

2.5.3. Effects of skewed mating and female breeding failure

We simulated two mating scenarios: (i) skewed mating (described in Section 2.4.4) which mimics the pattern observed on leks, and (ii) random mating. The random mating scenario was implemented by setting the mating skew parameter $\lambda$ (Section 2.4.4) to zero. We simulated each mating scenario at 10 levels of female breeding failure by varying the proportion of females reproducing from 0.1 to 1.0 at intervals of 0.1 .

\subsection{Statistical analyses}

Unless otherwise indicated, we report summary statistics as mean \pm standard error. Statistical analyses were conducted in Statview v5.0 (SAS Inc., Cary, North Carolina).

\section{Results}

\subsection{Empirical parameter estimates}

3.1.1. Population size $(\widehat{N})$

Table 3 gives sex-specific and total estimates of population size in each year with sample sizes and confidence intervals. Over both years, mean population size $(\widehat{N})$ for the focal study area was $168 \pm 13(n=2)$ with a population sex ratio of one male per $2.13 \pm 0.03$ females. After adjusting for omission of the two high elevation leks (Section 2.3), our population estimate for the entire San Miguel Basin was $216 \pm 4$.

\subsubsection{Survival $\left(v_{f}\right.$ and $\left.v_{m}\right)$}

Of marked individuals alive on April 1, 2003, 45\% of 20 females and $27 \%$ of 11 adult males were still alive a year later. Seven of 11 female and seven of eight male deaths occurred prior to June 1, 2003. Table 1 lists additional demographic parameters computed from these survival estimates.

\subsubsection{Female reproductive success}

Mean reproductive success among females alive on April 1 was low $\left(b_{f}=0.9 \pm 0.3\right.$ chicks per female, $n=$ 39 ) and the standardized variance in female reproductive success was correspondingly high $\left(I_{b_{f}}=4: 7\right)$. Three factors contributed to this pattern. First, $10 \mathrm{fe}-$ 
males $(26 \%)$ failed to hatch a brood because they died during the breeding season. Second, few nests $(27 \%$, summed over both first and second nesting attempts) were successful. Overall, only $21 \%$ of 39 females entering the breeding season, and $28 \%$ of 29 survivors, hatched any chicks. Finally, brood size among successful females was relatively low $(4.3 \pm 0.6$ chicks per female, $n=8$ ), due in part to low hatching success. Of 47 eggs found at seven successful nests after brood departure, $13(28 \%)$ had failed to hatch. Five unhatched eggs contained partially developed embryos while eight appeared unfertilized. In this sample, hatching failure reduced brood size from $6.7 \pm 0.4$, the sum of hatched and unhatched eggs, to $4.9 \pm 0.7$ (paired $t_{6}=2.9 ; p=0.03$ ).

\subsection{Modeled parameter estimates}

3.2.1. Standardized variance in annual male reproductive success

Simulations of male reproductive success yielded a mean $I_{b_{y}}$ value of $5.1 \pm 0.05$ among adult males. In the simulations, a mean of $43.8 \pm 0.2 \%$ of adults copulated but after clutch losses only $27.2 \pm 0.2 \%$ reproduced.

\subsubsection{Effective population size $\left(N_{e}\right)$}

Using input parameter values listed in Table 1 , our $N_{e}$ estimate for the study area was 33 with a $N_{e} / \tilde{N}$ ratio of 0.19 . Multiplying this ratio by the adjusted population estimate for the entire San Miguel Basin gives a $N_{e}$ value of 42 for the entire population.

\subsection{Effective population size simulations}

\subsubsection{Effect of population size}

Effective population size increased from 10 to 55 as population size increased from 47 to 313 . However, the $N_{e} / \tilde{N}$ ratio decreased as population size increased (Figure 1c; $p=0.0002$ ) due to an increase in the standardized variance in male reproductive success, $I_{b_{m}}$ (Figure $1 b ; p<0.0001$ ). This pattern is partially explained by a decrease in the proportion of males mating in larger populations (Figure 1a). To explore this pattern further, we examined the numerical distribution of matings on leks of different sizes (details not shown). Although the proportion of matings obtained by the top ranked male was higher on smaller leks, as specified by Kokko and Lindström (1997) skew model, the number of matings per top ranked male increased with lek size because more females mated at larger leks. In addition, a higher proportion of males mated on smaller leks. Both of these effects should increase the variance in reproductive male success in larger leks. Because mean lek size increases with population size, they explain why the standardized variance in male reproductive success also increased.
3.3.2. Effects of skewed mating and female breeding failure

Figure 2 plots simulated effective population size for random and skewed mating scenarios under different levels of female breeding failure. Effective population size was significantly lower under skewed than random mating (paired $t_{9}=8.7 ; p<0.0001$ ). However, the level of reduction in $N_{e}$ depended on the proportion of females reproducing. For example, skewed mating lowered $N_{e}$ by $31 \%$ when only $10 \%$ of females reproduced, but by $59 \%$ when all females reproduced. Female breeding failure also lowered effective population size $\left(N_{e}=35.8+6.0 * \ln\right.$ (proportion of females reproducing); $p<0.0001)$. For example, under skewed mating, $N_{e}$ was reduced by $23 \%$ when we lowered the percentage of female reproducing from $100 \%$ to $20 \%$, near the value observed in our population.

\section{Discussion}

Our empirically-based analyses suggest that the effective size of our study population was around 19\% of its census size and that both sexes, rather than just males, exhibit high variance in seasonal reproductive success. The simulations additionally predict the extent to which $N_{e}$ is lowered by both the skewed mating system and female breeding failure, and that mating skew will lower $N_{e} /{ }^{\hat{N}}$ more in larger populations. These conclusions are subject to at least three caveats.

First, our estimates of demographic parameters are based on only two years of data and longer term study might lead to different conclusions if female reproductive success or annual survival rates were particularly low during the study period. Effective population size would increase if female reproductive success were higher. For example, Figure 2 illustrates how $N_{e}$ responds to an increase in female nesting success. $N_{e}$

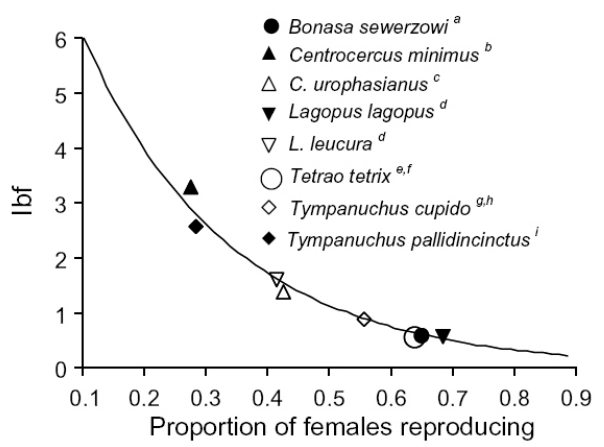

Figure 3 - Standardized variance in annual female reproductive success $\left(I_{b_{f}}\right)$ plotted as a function of the proportion of females reproducing for eight grouse species $\left(I_{b_{f}}=9.2 \mathrm{e}^{-4.2 x} ; p<0.0001\right) . L_{b_{f}}$ values were simulated using published estimates of female reproductive param-

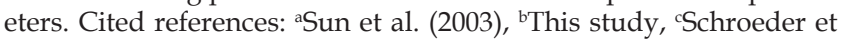
al. (1999), dSandercock et al. (2005a), ${ }^{\mathrm{e}}$ Willebrand (1992), ${ }^{\mathrm{f}}$ Caizergues and Ellison (2000), 'sMcKee et al. (1998), 'hyan et al. (1998), 'Pitman et al. (2006a). 
would also increase if annual survivorship were raised. For example, using formulas in Table 1 and Nunney's equation A2 (Section 2.4), a $20 \%$ increase in both male and female annual survival raises our $N_{e}$ estimate for the focal study area from 33 from 40 and $N_{e} / \widehat{N}$ from $19 \%$ to $24 \%$.

Second, we assumed that the mating system is adequately described by patterns of mating skew observed at leks. However, despite intensive lek monitoring we observed only $25-30 \%$ of females copulating annually (J.R. Stiver, unpublished data). Unseen matings could have occurred at leks during the evening display, on moonlight nights, or during the pre-dawn twilight when it was too dark to observe birds (Gibson et al., 1991). Additionally, some females might copulate away from leks entirely. Our results would be unaffected if those males observed mating on leks also monopolized unseen matings. However, if the males that were unsuccessful on leks performed relatively more unseen copulations, we would have overestimated the variance in male reproductive success and hence underestimated $N_{e}$.

Third, although a demographic estimate of $N_{e}$ would ideally be based on the variance in lifetime reproductive success (Hill, 1972), the short-term nature of our study limited us to an approximate method that substitutes seasonal for lifetime variance (Nunney, 1993, 1996; Nunney and Elam, 1994). Nunney's method assumes that an individual's seasonal reproductive success is a random draw from the seasonal distribution and that annual survival is independent of reproductive success. These assumptions would be violated, causing systematic biases in $N_{e}$ estimation, if reproductive success were age-dependent, individuals differed consistently in reproductive success across seasons, or seasonal reproductive success and survival were correlated. All of these patterns have been documented in long-term field studies of birds and mammals (Gibson and Guinness, 1980; Clutton-Brock, 1988; Newton, 1989; Stearns, 1992). Despite this, our use of Nunney's approach appears justified for two reasons. First, we found no difference in seasonal reproductive success between adult and yearling females in our study population (but see Aldridge and Brigham, 2001; Sandercock et al., 2005b) and we eliminated the major component of age-dependent reproductive success in males by considering only adult males as potential breeders (Gibson et al., 1991). Second, because only $27 \%$ of adult males and $45 \%$ of females survived from one year to the next (Table 1), there was limited scope for either individual differences in breeding success or correlations between success and survival to bias our $N_{e}$ estimate.

Other authors have recognized the potential for skewed mating to decrease $N_{e}$ by increasing the vari- ance in male reproductive success in lek breeding grouse (Bellinger et al., 2003; Johnson et al., 2003, 2004; Bouzat and Johnson, 2004). In our simulations, skewed mating reduced $N_{e}$ by $31-59 \%$ (depending on the proportion of females that reproduced) when compared to random mating. Random mating may be an overly conservative basis for comparison, however, because sexual selection presumably occurs in most animal populations (Shuster and Wade, 2003). Hence, this comparison on its own does not necessarily indicate that lek mating is associated with low $N_{e}$ values. Two other comparisons bear on this question, though not conclusively. Using estimates based on the demographic method we employed, Nunney (2000) suggested that the ratio of $N_{e} / N_{\text {breeders }}$ will usually lie between 0.25 and 0.75 . For our data this ratio is $0.23(33 / 145$, computed for the study area). With higher female nesting success this figure would exceed $25 \%$, but still remain towards the bottom of Nunney's proposed range. In contrast, our $N_{e} / \tilde{N}$ estimate of 0.19 exceeds the mean of many values, both demographic and genetic, synthesized by Frankham (1995) (0.11) and a genetic estimate of 0.10 for the lekking greater prairie chicken (Johnson et al., 2004). However, these comparisons are less informative because genetic estimates integrate all influences on $N_{e^{\prime}}$ including past population fluctuations, and should therefore yield lower values than demographic estimates, such as ours, that do not.

A novel prediction from the simulations is that $N_{e} /$ $\hat{N}$ should decline as population size increases. This effect arises because leks become larger as population size increases and, in larger leks, the variance in mating success is inflated because a smaller proportion of males mate and the number (though not the proportion) of matings by the most successful males increases. Although the predicted increase in the variance in male reproductive success with population size arises from a model of the dynamics of lek mating, this pattern has also been described in data from the polygynous, but non-lekking, red-winged blackbird (Weatherhead, 2005) and in flour beetles (Pray et al., 1996).

Reproductive success is often assumed to be more variable in males than females and consequently the relationship between male reproductive success and Ne has received considerable attention (Nunney, 1993; Storz et al., 2001, 2002). However, in our population, the standardized variance in seasonal reproductive success was almost as high in females (4.7) as in males (5.1). Our simulation results illustrate how increasing the rate of female breeding failure depresses $N_{e^{\prime}}$ by elevating the variance in female reproductive success (Figure 3). As illustrated in Figure 3, the standardized variance in seasonal reproductive success is also negatively correlated with the proportion of females reproducing 
across different species of grouse. This suggests that rates of female breeding failure should also be considered a potential influence on $N_{e}$ in other grouse. In our analyses, we assessed the proportion of females reproducing immediately after hatching. However, some female grouse lose their entire broods after chicks leave the nest, but within 2 weeks of hatching (Aldridge and Brigham, 2001; Sandercock et al., 2005b; Pitman et al., 2006b; Tirpak et al., 2006). This would further elevate breeding failure, increasing the variance in female reproductive success and lowering $N_{e}$.

The estimated effective size of our study population (42) was below the level at which inbreeding depression occurs in captive breeding studies and well below the level at which adaptive potential is predicted to decline (see Section 1). Lowered hatching success is a well-documented correlate of inbreeding in wild bird populations (van Noordwijk and Scharloo, 1981; Keller et al., 2006). Our hatching failure rate of $28 \%$ is similar to values reported for a bottlenecked and inbred population of the greater prairie-chicken (Tympanuchus cupido; Westemeier et al., 1998). Similarly, Briskie and Mackintosh (2004) found that hatching failure rates averaged $25 \%$ for 11 bird populations which had passed through severe population bottlenecks, whereas outbred bird populations average $10 \%$ (Koenig, 1982). Hence, while we cannot rule out non-genetic causes of low hatchability, the hatching success data are consistent with current inbreeding depression.

If the San Miguel Basin Gunnison sage-grouse population is experiencing inbreeding depression, the other small populations could also be at risk. To explore this issue, we estimated effective sizes of the remaining Gunnison sage-grouse populations by converting 2004 lek high counts for each population (Gunnison Sagegrouse Rangewide Steering Committee, 2005) to $\widehat{N}$ as described in Section 2, and then calculating $N_{e}$ for each population using the regression in Figure 1c. This procedure assumes that all populations exhibit similar demography to the San Miguel Basin, whereas fragmented bird populations may vary demographically (Engen et al., 2007). For the five smallest populations, extrapolated $N_{e}$ values ranged from 3 to 31 . If our regression were also valid for larger populations, $N_{e}$ in the largest population, the Gunnison Basin, would be 329. This suggests that six of the seven Gunnison sage-grouse populations may have effective sizes low enough to induce inbreeding depression and all seven could be losing adaptive potential. If so, long term persistence of the six smaller populations would require translocations to supplement genetic diversity.

\section{Acknowledgments}

We thank K. Tadvick, J. Bowers, A. Doll, J. Fletcher, C. Francis, T. Hanks, K. Hardie, C. Hisaoka, P. Kolar, A. LaGrange, F. Mayer, N.
Polato, and P. Shannon for field assistance, the San Miguel Basin landowners, the Colorado Division of Wildlife, the Rocky Mountain Center for Conservation Genetics and Systematics, and the USDA Forest Service Norwood Ranger District for logistic support, A. Tyre for assistance with model development, and E. Bergman, P. Dunn, C. Hagen, D. Leger, M. Phillips, D. Pilson and B. Sandercock for helpful comments on previous drafts. This work was funded by the Colorado Division of Wildlife. Field methods were approved by the University of Nebraska-Lincoln Institutional Animal Care and Use Committee and by the Colorado Division of Wildlife Animal Care and Use Committee.

References

Alatalo, R.V., Hoglund, J., Lundberg, A., Sutherland, W.J., 1992. The evolution of black grouse leks - female preferences benefit males in larger leks. Behavioral Ecology 3, 53-59.

Aldridge, C.L., Brigham, R.M., 2001. Nesting and reproductive activities of greater sage-grouse in a declining northern fringe population. Condor 103, 537-543.

Bellinger, M.R., Johnson, J.A., Toepfer, J., Dunn, P., 2003. Loss of genetic variation in greater prairie-chickens following a population bottleneck in Wisconsin, U.S.A. Conservation Biology 17, 717-724.

Bouzat, J.L., Johnson, K., 2004. Genetic structure among closely spaced leks in a peripheral population of lesser prairie-chickens. Molecular Ecology 13, 499-505.

Bowden, D.C., Kufeld, R.C., 1995. Generalized mark-sight population estimation applied to Colorado moose. Journal of Wildlife Management 59, 840-851.

Bradbury, J.W., Vehrencamp, S.L., Gibson, R.M., 1989. Dispersion of displaying male sage-grouse. I. Patterns of temporal variation. Behavioral Ecology and Sociobiology 24, 1-14.

Briskie, J.V., Mackintosh, M., 2004. Hatching failure increases with severity of population bottlenecks in birds. Proceedings of the $\mathrm{Na}$ tional Academy of Sciences USA 101, 558-561.

Caizergues, A., Ellison, L.N., 2000. Age-specific reproductive performance of black grouse Tetrao tetrix females. Bird Study 47, 344-351.

Clutton-Brock, T.H., 1988. Reproductive Success. University of Chicago Press, Chicago.

Crunden, C.W., 1963. Age and sex of sage-grouse from wings. Journal of Wildlife Management 27, 846-850.

Engen, S., Ringsby, T.H., Saether, B.-E., Lande, R., Jensen, H., Lillegård, M., Ellegren, H., 2007. Effective size of fluctuating populations with two sexes and overlapping generations. Evolution 61, $1,873-1,885$.

Frankham, R., 1995. Effective population size/adult population size ratios in wildlife: a review. Genetical Research 66, 95-107.

Frankham, R., 2005. Genetics and extinction. Biological Conservation 126, 131-140.

Frankham, R., Ballou, J.D., Briscoe, D.A., 2002. Introduction to Conservation Genetics. Cambridge University Press, Cambridge.

Futuyma, D.J., 1998. Evolutionary Biology, 3rd ed. Sinauer Associates, Sunderland, Mass.

Gibson, R.M., 1996. A re-evaluation of the hotspot settlement in lekking sage-grouse. Animal Behaviour 52, 993-1,005.

Gibson, R.M., Bachman, G.C., 1992. The costs of female choice in a lekking bird. Behavioral Ecology 3, 300-309.

Gibson, R.M., Bradbury, J.W., Vehrencamp, S.L., 1991. Mate choice in lekking sage-grouse revisited: the roles of vocal display, female site fidelity, and copying. Behavioral Ecology 2, 165-180.

Gibson, R.M., Guinness, F.E., 1980. Differential reproduction among red deer (Cervus elaphus) stags on Rhum. Journal of Animal Ecology 49, 199-203.

Giesen, K.M., Schoenberg, T.J., Braun, C.E., 1982. Methods for trapping sage-grouse in Colorado. Wildlife Society Bulletin 10, 224-231.

Gunnison Sage-grouse Rangewide Steering Committee, 2005. Gunnison Sage-grouse Rangewide Conservation Plan. Colorado Division of Wildlife, Denver.

Hedrick, P.W., 2005. Large variance in reproductive success and the $N_{e} / \widehat{N}$ ratio. Evolution 59, 1,596-1,599. 
Hill, W.G., 1972. Effective size of populations with overlapping generations. Theoretical Population Biology 3, 278-289.

Hood, G.M., 2005. PopTools version 2.6.6. Commonwealth Scientific and Industrial Research Organisation (CSIRO), Canberra, Australia. $<$ http://www.cse.csiro.au/poptools> (accessed February 2005).

Johnson, J.A., Bellinger, M.R., Toepfer, J.E., Dunn, P.O., 2004. Temporal changes in allele frequencies and low effective population size in greater prairie-chickens. Molecular Ecology 13, 2,617-2,630.

Johnson, J.A., Toepfer, J.E., Dunn, P.O., 2003. Contrasting patterns of mitochondrial and microsatellite population structure in fragmented populations of greater prairie-chickens. Molecular Ecology 12, 3,335-3,347.

Keller, L.F., Marr, A.B., Reid, J.M., 2006. The genetic consequences of small population size: inbreeding and loss of genetic variation. In: Smith, J.N.M., Keller, L.F., Marr, A.B., Arcese, P. (Eds.), Conservation and Biology of Small Populations. Oxford University Press, New York, pp. 113-137.

Kelly, M.J., 2001. Lineage loss in Serengeti cheetahs: consequences of high reproductive variance and heritability of fitness on effective population size. Conservation Biology 15, 137-147.

Koenig, W.D., 1982. Ecological and social factors affecting hatchability of eggs. Auk 99, 526-536.

Kokko, H., Lindström, J., 1997. Measuring the mating skew. American Naturalist 149, 794-799.

Lande, R., Barrowclough, G.F., 1987. Effective population size, genetic variation, and their use in population management. In: Soulé, M.E. (Ed.), Viable Populations for Conservation. Cambridge University Press, Cambridge, pp. 87-123.

McKee, G., Ryan, M.R., Mechlin, L.M., 1998. Predicting greater prairie-chicken nest success from vegetation and landscape characteristics. Journal of Wildlife Management 62, 314-321.

Newton, I., 1989. Lifetime Reproduction in Birds. Academic Press, London.

Nonacs, P., 2003. Measuring the reliability of skew indices: is there one best index? Animal Behaviour 65, 615-627.

Nunney, L., 1993. The influence of mating system and overlapping generations on effective population size. Evolution 47, 1,329-1,341.

Nunney, L., 1996. The influence of variation in female fecundity on effective population size. Biological Journal of the Linnean Society 59, 411-425.

Nunney, L., 2000. The limits to knowledge in conservation genetics. Evolutionary Biology 32, 179-194.

Nunney, L., Elam, D.R., 1994. Estimating the effective population size of conserved populations. Conservation Biology 8, 175-184.

Oyler-McCance, S.J., John, J.St., Taylor, S.E., Quinn, T.W., 2005. Population genetics of Gunnison sage-grouse: implications for management. Journal of Wildlife Management 69, 630-637.

Pitman, J.C., Hagen, C.A., Jamison, B.E., Robel, R.J., Loughin, T.M., Applegate, R.G., 2006a. Nesting ecology of lesser prairie-chickens in sand sagebrush prairie of southwestern Kansas. Wilson Journal of Ornithology 118, 23-35.

Pitman, J.C., Hagen, C.A., Jamison, B.E., Robel, R.J., Loughin, T.M., Applegate, R.G., 2006b. Survival of juvenile lesser prairie-chickens in Kansas. Wildlife Society Bulletin 34, 675-681.

Pray, L.A., Goodnight, C.J., Stevens, L., Schwartz, J.M., Yan, G.Y., 1996. The effect of population size on effective population size: an empirical study in the red flour beetle Tribolium castaneum. Genetical Research 68, 151-155.

Ryan, M.R., Burger, L.W., Jones, D.P., Wywialowski, A.P., 1998. Breeding ecology of greater prairie-chickens (Tympanuchus cupido) in relation to prairie landscape configuration. American Midland Naturalist 140, 111-121.

Sandercock, B.K., Martin, K., Hannon, S.J., 2005a. Life history strategies in extreme environments: comparative demography of arctic and alpine ptarmigan. Ecology 86, 2,176-2,186.

Sandercock, B.K., Martin, K., Hannon, S.J., 2005b. Demographic consequences of age-structure in extreme environments: population models for arctic and alpine ptarmigan. Oecologia 146, 13-24.
Schroeder, M.A., Young, J.R., Braun, C.E., 1999. Sage-grouse (Centrocercus urophasianus). In: Poole, A., Gill, F. (Eds.), The Birds of North America. The Birds of North America, Inc., Philadelphia, p. 425.

Semple, K., Wayne, R.K., Gibson, R.M., 2001. Microsatellite analysis of female mating behaviour in lek-breeding sage-grouse. Molecular Ecology 10, 2,043-2,048.

Shuster, S.M., Wade, M.J., 2003. Mating systems and strategies. In: Krebs, J.R., Clutton-Brock, T.H. (Eds.), Monographs in Behavior and Ecology. Princeton University Press, Princeton.

Stearns, S.C., 1992. The Evolution of Life Histories. Oxford University Press, Oxford.

Storz, J.F., Bhat, H.R., Kunz, T.H., 2001. Genetic consequences of polygyny and social structure in an Indian fruit bat, Cynopterus sphinx. II. Variance in male mating success and effective population size. Evolution 55, 1,224-1,232.

Storz, J.F., Ramakrishnan, U., Alberts, S.C., 2002. Genetic effective population size of a wild primate population: influence of current and historical demography. Evolution 56, 817-829.

Sun, Y.H., Swenson, J.E., Fang, Y., Klaus, S., Scherzinger, W., 2003. Population ecology of the Chinese grouse, Bonasa sewerzowi, in a fragmented landscape. Biological Conservation 110, 177-184.

Tirpak, J.M., Giuliano, W.M., Miller, C.A., Allen, T.J., Bittner, S., Buehler, D.A., Edwards, J.W., Harper, C.A., Igo, W.K., Norman, G.W., Seamster, M., Stauffer, D.F., 2006. Ruffed grouse population dynamics in the central and southern Appalachians. Biological Conservation 133, 364-378.

Turner, T.F., Richardson, L.R., Gold, J.R., 1999. Temporal genetic variation of mitochondrial DNA and the female effective population size of red drum (Sciaenops ocellatus) in the northern Gulf of Mexico. Molecular Ecology 8, 1,223-1,229.

van Noordwijk, A.J., Scharloo, W., 1981. Inbreeding in an island population of the great tit. Evolution 35, 674-688.

Wakkinen, W.L., Reese, K.P., Connelly, J.W., Fisher, R.A., 1992. An improved spotlighting technique for capturing sage-grouse. Wildlife Society Bulletin 20, 425-426.

Walsh, D.P., White, G.C., Remington, T.E., Bowden, D.C., 2004. Evaluation of the lek-count index for greater sage-grouse. Wildlife Society Bulletin 32, 56-68.

Weatherhead, P.J., 2005. Long-term decline in a red-winged blackbird population: ecological causes and sexual selection consequences. Proceedings of the Royal Society of London, Part B - Biological Sciences 272, 2,313-2,317.

Westemeier, R.L., Brawn, J.D., Simpson, S.A., Esker, T.L., Jansen, R.W., Walk, J.W., Kershner, E.L., Bouzat, J.L., Paige, K.N., 1998. Tracking the long-term decline and recovery of an isolated population. Science 282, 1,695-1,698.

White, G.C., 1996. NOREMARK: population estimation from markresighting surveys. Wildlife Society Bulletin 24, 50-53.

Widemo, F., Owens, I.P.F., 1995. Lek size, male mating skew, and the evolution of lekking. Nature 373, 148-151.

Widemo, F., Owens, I.P.F., 1999. Size and the stability of vertebrate leks. Animal Behaviour 58, 1,217-1,221.

Wiley, R.H., 1973. Territoriality and non-random mating in sage grouse, Centrocercus urophasianus. Animal Behaviour Monographs 6 , 85-169.

Wiley, R.H., 1974. Evolution of social organization and life history patterns among grouse. Quarterly Review of Biology 49, 201-227.

Willebrand, T., 1992. Breeding and age in female black grouse Tetrao tetrix. Ornis Scandinavica 23, 29-32.

Wright, S., 1938. Size of population and breeding structure in relation to evolution. Science 87, 430-431.

Young, J. R., 1994. The influence of sexual selection on phenotypic and genetic divergence among sage-grouse populations. Ph.D. thesis, Purdue University, West Lafayette, Ind.

Young, J.R., Braun, C.E., Oyler-McCance, S.J., Hupp, J.W., Quinn, T.W., 2000. A new species of sage-grouse (Phasianidae: Centrocercus) from southwestern Colorado. Wilson Bulletin 112, 445-453. 